\title{
Prognostic value of using glucosylceramide synthase and cytochrome P450 family 1 subfamily A1 expression levels for patients with triple-negative breast cancer following neoadjuvant chemotherapy
}

\author{
JIANNAN LIU $^{1 *}$, SHUHUA WANG ${ }^{2 *}$, CONGCONG WANG $^{1}$, XIANGSHUO KONG ${ }^{1}$ and PING SUN ${ }^{1}$ \\ Departments of ${ }^{1}$ Oncology and ${ }^{2}$ Medical Record Information, \\ Yantai Yuhuangding Hospital, Yantai, Shandong 264000, P.R. China
}

Received June 18, 2020; Accepted November 6, 2020

DOI: $10.3892 /$ etm.2021.9678

\begin{abstract}
Neoadjuvant chemotherapy (NACT) has been considered to be the preferred treatment option for early operable triple-negative breast cancer (TNBC). However, resistance to drugs remains to be the barrier to the efficacy of NACT. Glucosylceramide synthase (GCS) and cytochrome P450 family 1 subfamily A1 (CYP1A1) have been previously associated with drug resistance in breast cancer. The present study aimed to explore whether the expression levels of GCS and/or CYP1A1 are associated with the prognosis of TNBC after NACT. Immunohistochemistry was used to detect and measure GCS and CYP1A1 expression. Associations between GCS or CYP1A1 expression and the clinicopathological characteristics, pathological complete response (pCR), clinical complete response (cCR) and disease-free survival (DFS) were analyzed. GCS expression was found to be associated with tumor size $(\mathrm{P}=0.021)$ and $\mathrm{TNM}$ staging $(\mathrm{P}=0.042)$, whilst CYP1A1 expression was associated with lymph node metastasis $(\mathrm{P}=0.026)$ and $\mathrm{TNM}$ staging $(\mathrm{P}=0.034)$. The expression levels of GCS $(\mathrm{P}=0.024)$ and CYP1A1 $(\mathrm{P}=0.027)$ were upregulated after NACT. GCS and CYP1A1 expression were positively correlated $(\mathrm{P}=0.003 ; \mathrm{r}=0.327)$. No difference
\end{abstract}

Correspondence to: Dr Ping Sun, Department of Oncology, Yantai Yuhuangding Hospital, 20 Yuhuangding East Road, Yantai, Shandong 264000, P.R. China

E-mail: 81887294@qq.com

*Contributed equally

Abbreviations: GCS, glucosylceramide synthase; CYP1A1, cytochrome P450 family 1 subfamily A1; TNBC, triple-negative breast cancer; NACT, neoadjuvant chemotherapy; pCR, pathological complete response; cCR, clinical complete response; DFS, disease-free survival

Key words: glucosylceramide synthase, cytochrome P450 family 1 subfamily A1, neoadjuvant chemotherapy, triple-negative breast cancer was observed between the $\mathrm{GCS}^{+}(\mathrm{P}=0.188)$ or $\mathrm{CYP} 1 \mathrm{~A} 1^{+}$group $(\mathrm{P}=0.073)$ and the $\mathrm{GCS}^{-}$or $\mathrm{CYP}^{-} \mathrm{A1}^{-}$group in terms of $\mathrm{pCR}$. However, compared with that in the $\mathrm{GCS}^{+} \mathrm{CYP} 1 \mathrm{~A} 1^{+}$group, the pCR was markedly increased in the GCSCYP1A1- group $(\mathrm{P}=0.031)$. The cCR was lower in the $\mathrm{GCS}^{+}(\mathrm{P}=0.021)$ and CYP1A1 ${ }^{+}$groups $(\mathrm{P}=0.016)$ compared with in the $\mathrm{GCS}^{-}$or CYP1A1 ${ }^{-}$group. The DFS rate (57.9 vs. $65.4 \%$; $\left.\mathrm{P}=0.049\right)$ was lower in the $\mathrm{GCS}^{+} \mathrm{CYP} 1 \mathrm{~A} 1^{+}$group compared with that in the $\mathrm{GCS}^{-} \mathrm{CYP1} \mathrm{A1}^{-}$group. However, there was no statistical significance after P-value was adjusted for multiple comparisons using Bonferroni correction. In conclusion, co-expression of GCS and CYP1A1 was associated with pCR and DFS in TNBC, which may serve a role in the prediction of the prognosis of patients with TNBC following treatment with NACT.

\section{Introduction}

Breast cancer is the second leading cause of cancer-associated mortality after lung cancer in women worldwide (1). One of the breast cancer subtypes, triple-negative breast cancer (TNBC), which is characterized by the lack of estrogen and progesterone receptors and HER-2 expression, accounts for $15-20 \%$ of all breast cancers $(2,3)$. TNBC typically exhibits aggressive behaviors, including a high recurrence rate and early metastasis, resulting in poor prognoses $(4,5)$. Neoadjuvant chemotherapy (NACT) can facilitate breast conservation, render inoperable tumors operable and provide important prognostic information based on the response to therapy $(6,7)$. In addition, NACT is considered to be a treatment option for patients with early operable TNBC (6). The criterion for determining the response to NACT is the tumor pathological complete response (pCR), which is defined as the absence of residual cancer in the primary breast tumor and lymph nodes (8). Achievement of pCR following NACT is associated with good long-term outcomes (9-11). Although TNBC is initially sensitive to chemotherapy, it rapidly develops drug resistance such that only $10-40 \%$ of patients can achieve pCR $(12,13)$. A number of clinical trials have previously attempted to apply novel agents, such as immunotherapy and anti-angiogenetic agents to increase the pCR but adverse side effects have limited their potential application in clinical 
practice $(14,15)$. Additionally, not all increases in pCR lead to an improvement of long-term outcomes $(11,16)$. Therefore, development of novel specific biomarkers may help to identify patients who would benefit from NACT.

Glucosylceramide synthase (GCS) is a glycosyltransferase that transfers a glucose group from uridine diphospho-glucose to ceramide to produces glucosylceramide $(17,18)$. GCS expression is upregulated in a number of multidrug resistance (MDR) cancer cell lines, including breast cancer $(18,19)$, leukemia (20) and renal cell cancer (21) cell lines. Previous studies have reported that GCS was associated with MDR to anthracycline drugs in breast cancer, where GCS expression was upregulated in $30 \%$ of patients with TNBC $(22,23)$. Although there is at present no standard regimen for NACT, anthracycline and taxanes are commonly used for NACT treatment (24).

Among a number of factors which can induce drug resistance, one proposed mechanism is the activation or inactivation of drug-metabolizing enzymes. The cytochrome P450 (CYP) family is a multigene family of enzymes that has been implicated in the metabolism of a diverse range of drugs (25). In particular, CYP family 1 subfamily A1 (CYP1A1) belongs to the CYP family, which is an enzyme that is involved in the bioactivation of endogenous and environmentally reactive compounds, such as dimethylbenz(a)anthracene and heterocyclic amine, 2-amino-1-methyl-6-phenylimidazo[4,5b]pyridine. In addition, CYP1A1 can also bind to DNA to mediate carcinogenesis (26). CYP1A1 colocalizes with P-glycoprotein and contributes to tumor cell chemoresistance by enhancing the metabolism of numerous drugs (27-30).

Therefore, the present study explored the association between GCS and CYP1A1 expression in TNBC, by analyzing their association with clinicopathological parameters, pCR and disease-free survival (DFS) following NACT. In addition, the present study also focused on the possibility that GCS is associated with responses to NACT and that in can be used to predict prognosis following anthracycline- or taxanes-based NACT regimen in TNBC.

\section{Materials and methods}

Patients. In total, 80 female patients with a median age of 56 years (range, 24-72 years), who met the following inclusion criteria between January 1, 2012 and February 31, 2014 at Yuhuangding Hospital Affiliated to Qingdao University (Yantai, China) were eligible for the present study: i) Age $\geq 18$ years, core needle biopsy diagnosis of invasive breast cancer and immunohistochemistry-confirmed estrogen receptor (ER) expression to be $<1 \%$ positive, progesterone receptor (PR) expression to be $<1 \%$ positive and HER-2 score 0 or 1-2+, if a Her-2 score of $2+$ was found, fluorescence in situ hybridization was used to further test for Her-2 negativity as previously described (31); ii) patients underwent $\geq 2$ cycles of NACT and were demonstrated to have operable breast cancer (stage IIA-IIIB); iii) all tumors of the patients were deemed by at least a CT scan as having one measurable lesion; iv) Eastern Cooperative Oncology Group score of 0-2 (32); v) normal routine blood tests reporting hemoglobin levels of $\geq 100 \mathrm{~g} / \mathrm{l}$, leukocyte count $\geq 4 \times 10^{9} / 1$, neutrophil count $\geq 1.5 \times 10^{9} / 1$, thrombocyte count $\geq 100 \times 10^{9} / 1$ and liver and kidney functions within $\leq 1.5 \mathrm{X}$ of the normal range; vi) no previous therapy, including chemotherapy, radiotherapy, endocrine therapy, immunotherapy or surgery, for breast cancer; and vii) life expectancy $>6$ months.

The exclusion criteria were as follows: i) Patients with active concomitant malignancy; ii) patients with active infection and serious concomitant diseases, including heart failure, severe diabetes, liver failure, severe peripheral neuropathy or severe drug allergy; and iii) pregnant or lactating. The characteristics of all patients are presented in Table I.

Written informed consent was obtained from all individual participants included in the present study before treatment. The present study was conducted in accordance with the Declaration of Helsinki. The present study was approved by the Institutional Review Board, Medical Ethics Committee of Yantai Yuhuangding Hospital (Yantai, China).

NACT treatment. NACT (33-36) was administered every 21 days. The present study used an AT regimen (doxorubicin $50 \mathrm{mg} / \mathrm{m}^{2}+$ docetaxel $75 \mathrm{mg} / \mathrm{m}^{2}$ or paclitaxel $\left.175 \mathrm{mg} / \mathrm{m}^{2}\right)$ in the majority of the cases. An AC regimen (doxorubicin $60 \mathrm{mg} / \mathrm{m}^{2}+$ cyclophosphamide $600 \mathrm{mg} / \mathrm{m}^{2}$ ), TC regimen (docetaxel $75 \mathrm{mg} / \mathrm{m}^{2}+$ cyclophosphamide $600 \mathrm{mg} / \mathrm{m}^{2}$ ) or AC-Follow T regimen (four cycles of doxorubicin $60 \mathrm{mg} / \mathrm{m}^{2}+$ cyclophosphamide $600 \mathrm{mg} / \mathrm{m}^{2}$, followed by four cycles of docetaxel $75 \mathrm{mg} / \mathrm{m}^{2}$ or paclitaxel $175 \mathrm{mg} / \mathrm{m}^{2}$ ) was used in the remaining cases. Most of patients received 6 cycles of chemotherapy.

Response to NACT assessment. Tumor staging was performed according to the Eighth Edition of the guidelines of the American Joint Committee on Cancer (37). The primary objective was to evaluate the PCR rate, which is defined as no histological evidence of residual invasive tumor cells in the breast and axillary lymph nodes (ypT0/TisypN0) (38). Residual tumors were defined as non-pCR and were classified using a pathological TNM system (36). The secondary objective was to evaluate the clinical response rate and DFS. Clinical tumor response was assessed according to the Response Evaluation Criteria in Solid Tumors version 1.1 (39): i) Complete response (cCR) was defined as the disappearance of all tumor foci after chemotherapy; ii) partial response was defined as $\geq 30 \%$ decline in the maximum tumor diameters; iii) progressive disease was defined as $\geq 20 \%$ increase in the cumulative measurement of all tumor diameters from the baseline; and iv) stable disease was confirmed when complete response, partial response or progressive disease was not noted. DFS was defined as the time from the date of surgery to the first observation of tumor recurrence (metastatic recurrence and/or local relapse) or death. Patients who remained alive without recurrence and/or metastasis were administratively censored at the last follow-up date. All patients who received chemotherapy (>one cycle of each regimen) were evaluated. All patients were followed up for a median period of 68.8 months (range, 33.0-84.0 months) after surgery.

Immunohistochemistry. Tumor specimens were obtained from patients included in this study before NACT and after surgery. All specimens were fixed with $10 \%$ formalin for 6-24 $\mathrm{h}$ at room temperature, paraffin embedded and cut into $4-\mu \mathrm{m}$ sections. The slides were allowed to dry overnight at 
Table I. Clinicopathological characteristics of patients with triple-negative breast cancer in the present study.

\begin{tabular}{lc}
\hline Clinical characteristics & Number (\%) \\
\hline Age, years & \\
$<35$ & $6(7.50)$ \\
$35-60$ & $46(57.50)$ \\
$>60$ & $28(35.00)$ \\
Grade & \\
I & $9(11.25)$ \\
II & $45(56.25)$ \\
III & $26(32.50)$ \\
Node & \\
0 & $25(31.25)$ \\
$0-3$ & $19(23.75)$ \\
4 & $36(45.00)$ \\
Tumor size & \\
T1-2 & $44(55.00)$ \\
T3-T4 & $36(45.00)$ \\
Ki67 & \\
$<14 \%$ & $16(20.00)$ \\
$\geq 14 \%$ & $64(80.00)$ \\
TNM stage & \\
IIA-B & $29(36.25)$ \\
IIIA-B & $51(63.75)$ \\
\hline
\end{tabular}

room temperature. To deparaffinize the sections, they were placed in two containers of xylene at room temperature for 5 min each. To start rehydration, the sections were placed in three containers of $100 \%$ ethanol, $95 \%$ ethanol and $85 \%$ ethanol at room temperature for $5 \mathrm{~min}$ each. Antigen retrieval was performed in a microwave oven at $100^{\circ} \mathrm{C}$ for $15 \mathrm{~min}$ in $10 \mathrm{mM}$ citrate buffer (pH 6.0). For all samples, endogenous peroxidase activity was blocked for $10 \mathrm{~min}$ using a $3 \% \mathrm{H}_{2} \mathrm{O}_{2}$-methanol solution at room temperature. The slides were blocked with $10 \%$ normal goat serum (Dako; Agilent Technologies, Inc.) at room temperature for $10 \mathrm{~min}$ and incubated with appropriately diluted primary antibodies overnight at $4^{\circ} \mathrm{C}$. The antibodies against ER (ready-to use, no dilution; cat. no. 790-4325), PR (ready-to use, no dilution; cat. no. 790-4296), HER-2 (ready-to use, no dilution; cat. no. 790-4493) and Ki67 (ready-to use, no dilution; cat. no. 790-4286) were purchased from Roche Diagnostics. CYP1A1 antibody was purchased from LifeSpan BioSciences, Inc. (dilution, 1:50; cat. no. LS-C99804). GCS antibody was purchased from BIOSS (dilution, 1:300; cat. no. bs-0701R). Subsequently, the slides were probed with a horseradish peroxidase-labeled polymer conjugated to an appropriate secondary antibody (DAB + substrate chromogen system; cat. no. GK600505; Dako; Agilent Technologies, Inc.) for $30 \mathrm{~min}$. The slides were incubated DAB+ (DAB + substrate chromogen system cat. no. GK600505; Dako; Agilent Technologies, Inc.) at $25^{\circ} \mathrm{C}$ for $5-15$ min until there were yellow to brown granules visible when viewed under a light microscope. The stained sections were then observed under a light microscope (magnification, $\mathrm{x} 400$; Nikon eclipse 80i; Nikon Corporation).

A dual semi-quantitative scale combining staining intensity and percentage of positive cells was used to evaluate GCS and CYP1A1 protein staining. Each index counted 10 high power microscopic fields, containing at least 1,000 tumor cells. The staining intensity of the cell plasma was scored as 0 (negative), 1 (weak), 2 (moderate) or 3 (strong). The percentage of positive cells was scored as follows: i) 0 , no staining or staining in $<5 \%$ of tumor cells; ii) 1 , staining in $5-25 \%$ of cells; iii) 2 , staining in $26-50 \%$ of cells; iv) 3 , staining in $51-75 \%$ of cells; and v) 4 , staining in $>75 \%$ of cells. The staining intensity and the percentage were then multiplied to obtain a final score (range, 0-12). For GCS and CYP1A1 expression, cytoplasmic staining was considered positive with a score $>4$, or negative with an immunohistochemical score $\leq 4(22,23,40)$.

Transfection with GCS plasmid. The breast cancer cell lines MDA-MB-453 (ATCC HTB-131; https://www.atcc. org/products/all/HTB-131.aspx) and MDA-MB-231 (ATCC HTB-26; https://www.atcc.org/products/all/HTB-26.aspx) were obtained from the ATCC. The full-length GCS vector pcDNA3.1-GCS was synthesized and purified by Shanghai GenePharma Co., Ltd. Prior to transfection, cells were cultured in PRMI-1640 with 10\% FBS (Gibco; Thermo Fisher Scientific, Inc.) and seeded into six-well plates at the density of $1 \times 10^{6}$ cells per well and incubated at $37^{\circ} \mathrm{C}$ in an atmosphere with $5 \% \mathrm{CO}_{2}$ for $12 \mathrm{~h}$. For each well, $10 \mu \mathrm{l}(2 \mathrm{mg} / \mathrm{ml})$ Lipofectamine ${ }^{\circledR} 2000$ (Invitrogen; Thermo Fisher Scientific, Inc.) and $5 \mu 1(1 \mathrm{mg} / \mathrm{ml})$ vector were diluted into $250 \mu 1$ RPMI-1640 (Gibco; Thermo Fisher Scientific, Inc.) culture medium without serum. After incubation for $10 \mathrm{~min}$ at room temperature, the diluted vector and Lipofectamine were mixed together and incubated for $20 \mathrm{~min}$ at $25^{\circ} \mathrm{C}$. The mixture was then added to the cells. The medium was replaced with $1 \mathrm{ml}$ complete RPMI-1640 culture medium $6 \mathrm{~h}$ later, so that the final concentration of the plasmid was $5 \mu \mathrm{g} / \mathrm{ml}$. As negative control, $10 \mu \mathrm{l}$ Lipofectamine and $5 \mu \mathrm{l}$ $(1 \mathrm{mg} / \mathrm{ml})$ pcDNA3.1 were also transfected into the two cell lines. Forty-eighrt hours after the transfection, the subsequent experiments were performed.

RNA extraction and quantitative PCR $(q P C R)$. Total RNA from the cell lines was isolated using TRIzol ${ }^{\circledR}$ reagent (Invitrogen; Thermo Fisher Scientific, Inc.) according to manufacturer's protocol. Reverse transcription was performed using a Toyobo First Strand cDNA Synthesis kit (cat. no. FSQ-201; Toyobo Life Science). A total of $1 \mu 1 \mathrm{RNA}$ was added into $10 \mu \mathrm{l}$ reaction solutions according to the manufacturer's protocol and the reaction conditions were as follows: $37^{\circ} \mathrm{C}$ for $15 \mathrm{~min}$ and $95^{\circ} \mathrm{C}$ for 5 min. qPCR was performed using a SYBR ${ }^{\circledR}$ Green RealTime PCR Master Mix (Toyobo Life Science). The primers for GCS were forward, 5'-CCTTTCCTCTCCCCACCTTCC TCT-3' and reverse, 5'-GGTTTCAGAAGAGAGACACCT GGG-3' (41). The primers for CYP1A1 were forward, 5'-CTC AGCTCAGTACCTCAGCCAC-3' and reverse, 5'-CCCCAT ACTGCTGGCTCATC- 3 '. The primers for the $\beta$-actin were forward, 5'-ACCCCCACTGAAAAAGATGA-3' and reverse, 5'-ATCTTCAAACCTCCATGATG-3', which was used as an internal control. The final volume was $25 \mu 1$ and an iCycler iQ Real-Time PCR Detection System (Bio-Rad Laboratories, 
Table II. Association between GCS or CYP1A1 expression and clinical features.

\begin{tabular}{|c|c|c|c|c|c|c|}
\hline Clinical characteristics & $\mathrm{GCS}^{+}, \mathrm{n}(\%)$ & $\mathrm{GCS}^{-}, \mathrm{n}(\%)$ & P-value & $\mathrm{CYP} \mathrm{A} 1^{+}, \mathrm{n}(\%)$ & CYP1A1', n (\%) & P-value \\
\hline \multicolumn{7}{|l|}{ Age, years } \\
\hline$<35$ & $4(5.00)$ & $2(2.50)$ & \multirow[t]{2}{*}{0.137} & $3(3.75)$ & $3(3.75)$ & \multirow[t]{2}{*}{0.284} \\
\hline$>35$ & $21(26.25)$ & $53(66.25)$ & & $16(20.00)$ & $58(72.50)$ & \\
\hline \multicolumn{7}{|l|}{ Grade } \\
\hline I & $2(2.50)$ & $7(8.75)$ & \multirow[t]{2}{*}{0.811} & $3(3.75)$ & $6(7.50)$ & \multirow[t]{2}{*}{0.763} \\
\hline II-III & $23(28.75)$ & $48(60.00)$ & & $16(20.00)$ & $55(68.75)$ & \\
\hline \multicolumn{7}{|l|}{ Node } \\
\hline N0 & $5(6.25)$ & $20(25.00)$ & \multirow[t]{2}{*}{0.143} & $2(2.50)$ & $23(28.75)$ & \multirow[t]{2}{*}{0.026} \\
\hline N1-N3 & $20(25.00)$ & $35(43.75)$ & & $17(21.25)$ & $38(47.50)$ & \\
\hline \multicolumn{7}{|l|}{ Tumor size } \\
\hline T1-T2 & $9(11.25)$ & $35(43.75)$ & \multirow[t]{2}{*}{0.021} & $7(8.75)$ & $37(46.25)$ & \multirow[t]{2}{*}{0.068} \\
\hline T3-T4 & $16(20.00)$ & $20(25.00)$ & & $12(15.00)$ & $24(30.00)$ & \\
\hline \multicolumn{7}{|l|}{ Ki67 } \\
\hline$<14 \%$ & $7(8.75)$ & $9(11.25)$ & \multirow[t]{2}{*}{0.228} & $6(7.50)$ & $10(12.50)$ & \multirow[t]{2}{*}{0.264} \\
\hline$\geq 14 \%$ & $18(22.50)$ & $46(57.50)$ & & $13(16.25)$ & $51(63.75)$ & \\
\hline \multicolumn{7}{|l|}{ TNM stage } \\
\hline IIA-IIB & $5(6.25)$ & $24(30.00)$ & \multirow[t]{2}{*}{0.042} & $3(3.75)$ & $26(32.50)$ & \multirow[t]{2}{*}{0.034} \\
\hline IIIA-IIIB & $20(25.00)$ & $31(38.75)$ & & $16(20.00)$ & $35(43.75)$ & \\
\hline \multicolumn{7}{|l|}{ NACT } \\
\hline Before & $25(31.25)$ & $55(68.75)$ & \multirow[t]{2}{*}{0.024} & 19 (23.75) & $61(76.25)$ & \multirow[t]{2}{*}{0.027} \\
\hline After & $39(48.75)$ & $41(51.25)$ & & $32(40.00)$ & $48(60.00)$ & \\
\hline \multicolumn{7}{|l|}{$\mathrm{pCR}$} \\
\hline Yes & $9(11.25)$ & $15(18.75)$ & \multirow[t]{2}{*}{0.188} & $6(7.50)$ & $18(22.50)$ & \multirow[t]{2}{*}{0.073} \\
\hline No & $30(37.50)$ & $26(32.50)$ & & $26(32.50)$ & $30(37.50)$ & \\
\hline \multicolumn{7}{|l|}{$\mathrm{cCR}$} \\
\hline Yes & $11(13.75)$ & $22(27.50)$ & \multirow[t]{2}{*}{0.021} & $8(10.00)$ & $25(31.25)$ & \multirow[t]{2}{*}{0.016} \\
\hline No & $28(35.00)$ & $19(23.75)$ & & $24(30.00)$ & $23(28.75)$ & \\
\hline
\end{tabular}

GCS, glucosylceramide synthase; CYP1A1, cytochrome P450 family 1 subfamily A1; NACT, neoadjuvant chemotherapy; pCR, pathological complete response; cCR, clinical complete response.

Inc.) was used for qPCR. The thermocycling conditions for the qPCR reaction were as follows: Initial denaturation for $5 \mathrm{~min}$ at $94^{\circ} \mathrm{C}$; followed by 35 cycles of denaturation for $30 \mathrm{sec}$ at $94^{\circ} \mathrm{C}$, primer annealing for $30 \mathrm{sec}$ at $60^{\circ} \mathrm{C}$ and polymerization for $30 \mathrm{sec}$ at $72^{\circ} \mathrm{C}$; and a final extension for $10 \mathrm{~min}$ at $72^{\circ} \mathrm{C}$. The relative mRNA expressions were calculated using the $2^{-\Delta \Delta} \mathrm{Cq}$ method (42).

Statistical analysis. Data were analyzed using the SPSS software (version 18.0; SPSS, Inc.). $\chi^{2}$ test was used in the table presented in Tables I and II. In Table III, P1 represented a comparison between the $\mathrm{GCS}^{+} \mathrm{CYP} 1 \mathrm{~A} 1^{-}$and $\mathrm{GCS}^{+} \mathrm{CYP} 1 \mathrm{~A} 1^{+}$group; $\mathrm{P} 2$ represented a comparison between

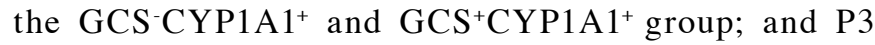
represented a comparison between the $\mathrm{GCS}^{-} \mathrm{CYP} 1 \mathrm{~A} 1^{-}$and $\mathrm{GCS}^{+} \mathrm{CYP} 1 \mathrm{~A} 1^{+}$group. Spearman's rank correlation coefficient was used to analyze the correlation between the immunohistochemical scores of GCS and CYP1A1. DFS curves were generated according to the Kaplan-Meier method and the survival between groups was compared using log-rank test.
P-values were adjusted for multiple comparisons using the Bonferroni correction. For the multiple comparisons of DFS rate, $\mathrm{P}<0.017(0.05 / 3)$ was defined as statistically significant. For other tests, $\mathrm{P}<0.05$ was considered to indicate a statistically significant difference. All P-values were the results of two-sided tests.

\section{Results}

Association between GCS and CYPIA1 and the clinicopathologic parameters in TNBC. Cell experiments were performed to assess the potential association between GCS and CYP1A1 (Fig. S1). A total of 80 patients with TNBC who had undertaken NACT were enrolled into the present study. Clinical and pathological TNM classifications of patients were evaluated according to the Eighth Edition American Joint Committee on Cancer Staging Criteria (37). Immunohistochemical staining was performed to detect the expression levels of GCS and CYP1A1. GCS and CYP1A1 staining were mainly observed in the cytoplasm of cancer cells (Fig. 1). The association 
Table III. Association between GCS and CYP1A1 co-expression and pCR.

\begin{tabular}{lccccccr}
\hline Outcome & $\begin{array}{c}\mathrm{GCS}^{+} \mathrm{CYP1A1} 1^{+}, \\
\mathrm{n}(\%)\end{array}$ & $\begin{array}{c}\mathrm{GCS}^{+} \mathrm{CYP1A1} \\
\mathrm{n}(\%)\end{array}$ & P1-value & $\begin{array}{c}\mathrm{GCSCYP1A1}^{+}, \\
\mathrm{n}(\%)\end{array}$ & P2-value & $\begin{array}{c}\text { GCSCYP1A1 } \\
\mathrm{n}(\%)\end{array}$ & P3-value \\
\hline pCR & $2(2.50)$ & $7(8.75)$ & 0.127 & $3(3.75)$ & 0.374 & $11(13.75)$ & 0.031 \\
Non-pCR & $17(21.25)$ & $13(16.25)$ & & $10(12.50)$ & & $17(21.25)$ & \\
\hline
\end{tabular}

GCS, glucosylceramide synthase; CYP1A1, cytochrome P450 family 1 subfamily A1; pCR, pathological complete response.
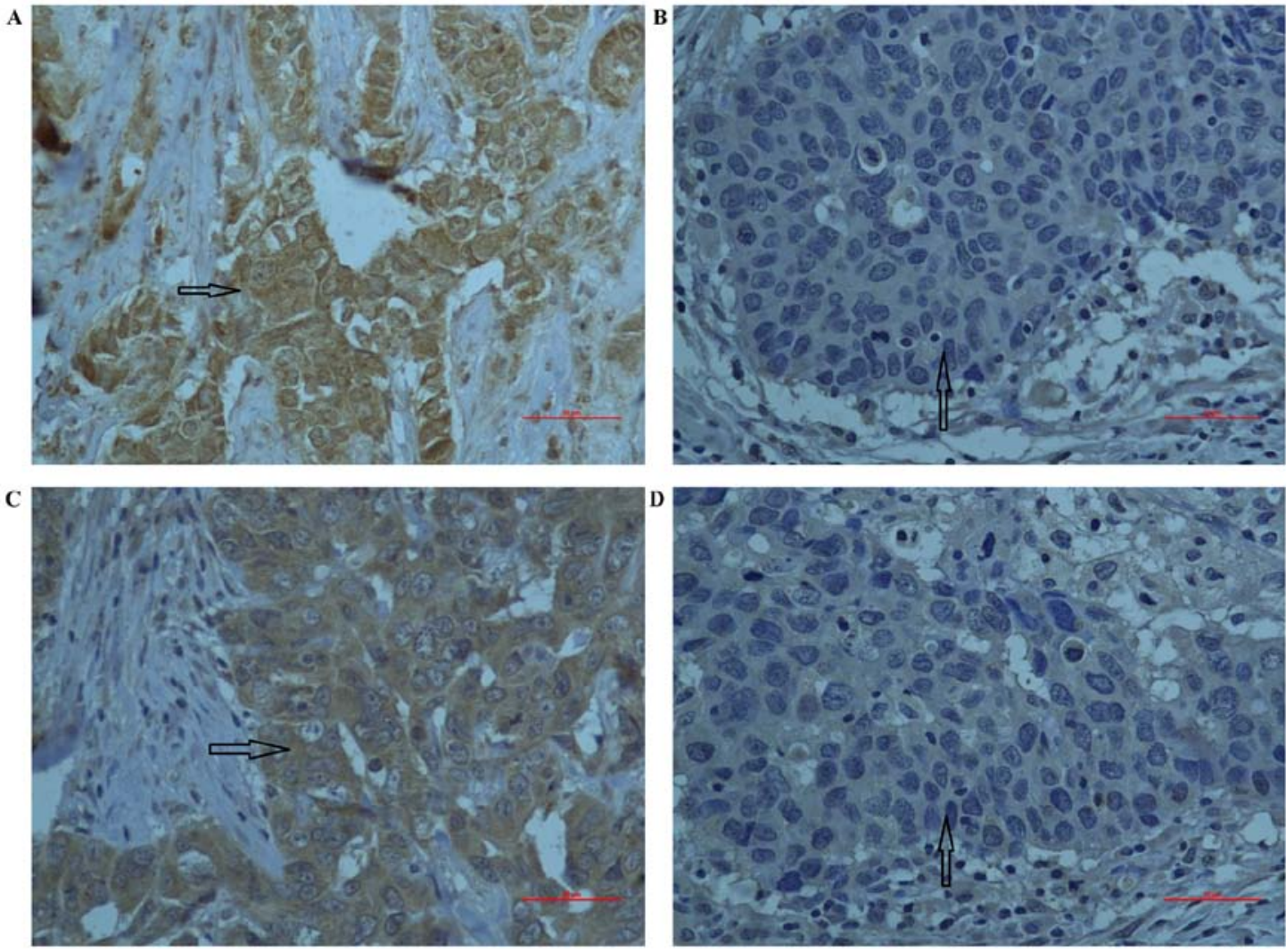

Figure 1. Expression levels of GCS and CYP1A1 in patients with triple-negative breast cancer. Representative immunohistochemistry images of (A) GCS ${ }^{+}$ (B) GCS ${ }^{-}$, (C) CYP1A1 ${ }^{+}$and (D) CYP1A1 tissue sections. Scale bars, $50 \mu \mathrm{m}$. CYP1A1, cytochrome P450 family 1 subfamily A1; GCS, glucosylceramide synthase.

between GCS or CYP1A1 expression and each of the clinicopathological parameters were subsequently analyzed. The expression levels of GCS were found to be associated with tumor size $(\mathrm{P}=0.021)$ and TNM stage $(\mathrm{P}=0.042)$. In addition, the expression levels of CYP1A1 were associated with lymph node metastasis $(\mathrm{P}=0.026)$ and TNM stage $(\mathrm{P}=0.034)$. No other clinicopathologic parameters were associated with GCS or CYP1A1 expression (Table II).

Association between GCS and CYPIAl expression and NACT in $T N B C$. The present study also measured the expression levels of GCS and CYP1A1 before NACT and after surgery using immunohistochemistry. The positive expression of GCS was increased from 31.25 to $48.75 \%$ after NACT. The positive expression of CYP1A1 was also increased from 23.75 to $40.0 \%$ after NACT. Upregulation of both GCS $(\mathrm{P}=0.024)$ and CYP1A1 ( $\mathrm{P}=0.027)$ expression were found to be associated with NACT (Table II). Furthermore, Spearman's rank correlation analysis revealed that there was a significant but weak correlation between GCS and CYP1A1 expression in the TNBC tissues ( $\mathrm{P}=0.003$; $\mathrm{r}=0.327$; Fig. 2).

Association of GCS and CYPIAI expression with the pathological response to NACT in TNBC. pCR was defined as no histological evidence of residual invasive tumor cells in the breast and axillary lymph nodes (ypT0/TisypN0). Due to the upregulation of GCS and CYP1A1 expression, the present study next analyzed the possible association between the expression levels of GCS or CYP1A1 and pCR. There was no difference in $\mathrm{pCR}$ in the $\mathrm{GCS}^{+}(\mathrm{P}=0.188)$ or $\mathrm{CYP} 1 \mathrm{Al}^{+}$group $(\mathrm{P}=0.073)$ compared with that in the GCS ${ }^{-}$or CYP1A1- group (Table II).

cCR was defined as the disappearance of all tumor foci after chemotherapy. cCR rate in the $\mathrm{GCS}^{+}$group was $28.20 \%$ (11/39), which was lower compared with $53.7 \%$ (22/41) in the 


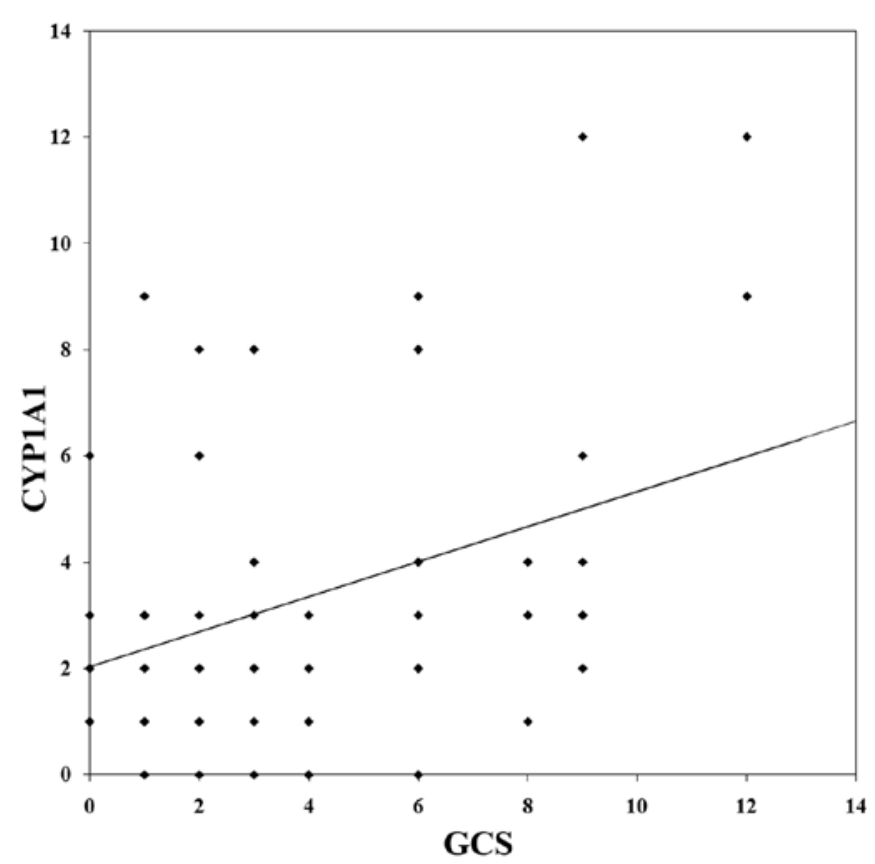

Figure 2. Correlation analysis between GCS and CYP1A1 expression in triple-negative breast cancer. CYP1A1, cytochrome P450 family 1 subfamily A1; GCS, glucosylceramide synthase.

GCS group $(\mathrm{P}=0.021)$. The cCR rate in the $\mathrm{CYP}^{-1} 1^{+}$group was $25.0 \%$ (8/32), which was lower compared with $52.1 \%$ (25/48) in the CYP1 A $^{-}$group $(\mathrm{P}=0.016$; Table II).

Among the 80 cases of TNBC, 19 cases were $\mathrm{GCS}^{+} \mathrm{CYP} \mathrm{Al}^{+}, 20$ cases were $\mathrm{GCS}^{+} \mathrm{CYP}^{-} \mathrm{Al}^{-}, 13$ cases were $\mathrm{GCS}^{-} \mathrm{CYP} \mathrm{Al}^{+}$and 28 cases were GCS CYP1A1. Compared with that in the $\mathrm{GCS}^{+} \mathrm{CYP} 1 \mathrm{Al}^{+}$group, incidences of $\mathrm{pCR}$ was increased in the GCSCYP1A1 group $(\mathrm{P}=0.031)$. However, no significant association was observed between the incidences of pCR between the $\mathrm{GCS}^{+} \mathrm{CYP} 1 \mathrm{~A} 1^{+}$and the $\mathrm{GCS}^{+} \mathrm{CYP} 1 \mathrm{~A} 1^{-}$or GCSCYP1A1 $1^{+}$groups (Table III).

Association of GCS and CYPIAl expression with the prognosis following NACT in TNBC. The association between GCS or CYP1A1 and DFS was subsequently analyzed by Kaplan-Meier survival analysis. There was no difference between the DFS of patients in the $\mathrm{GCS}^{+}(\mathrm{P}=0.301$; Fig. $3 \mathrm{~A})$ or $\mathrm{CYP}^{\mathrm{A}} 1^{+}(\mathrm{P}=0.099$; Fig. 3B) groups and their corresponding negative groups. DFS of patients in the GCS CYP1A1 group was compared with the other three groups. No statistically significant difference was observed between the DFS of GCSCYP1A1 ${ }^{+}$and $\mathrm{GCSCCYP}^{-} \mathrm{Al}^{-}$group (61.5 vs. $65.4 \%$; $\mathrm{P}=0.497$ ). Similar result was observed between the DFS of $\mathrm{GCS}^{+} \mathrm{CYP1A1}{ }^{-}$and $\mathrm{GCSC}^{-} \mathrm{CYP1A1} 1^{-}$group (65.0 vs. 65.4\%; $\mathrm{P}=0.734)$. The DFS of patients in the $\mathrm{GCS}^{+} \mathrm{CYP} 1 \mathrm{~A} 1^{+}$ group exhibited markedly worse DFS rate compared with that in the GCSCYP1A1 ${ }^{-}$group (57.9 vs. $65.4 \%$; $\left.\mathrm{P}=0.049\right)$. However, after the significance threshold was corrected using Bonferroni correction, there was no statistical significance between the two groups (Fig. 3C).

\section{Discussion}

TNBC represents a heterogeneous group of tumors based on gene expression profiling (43). Results from the
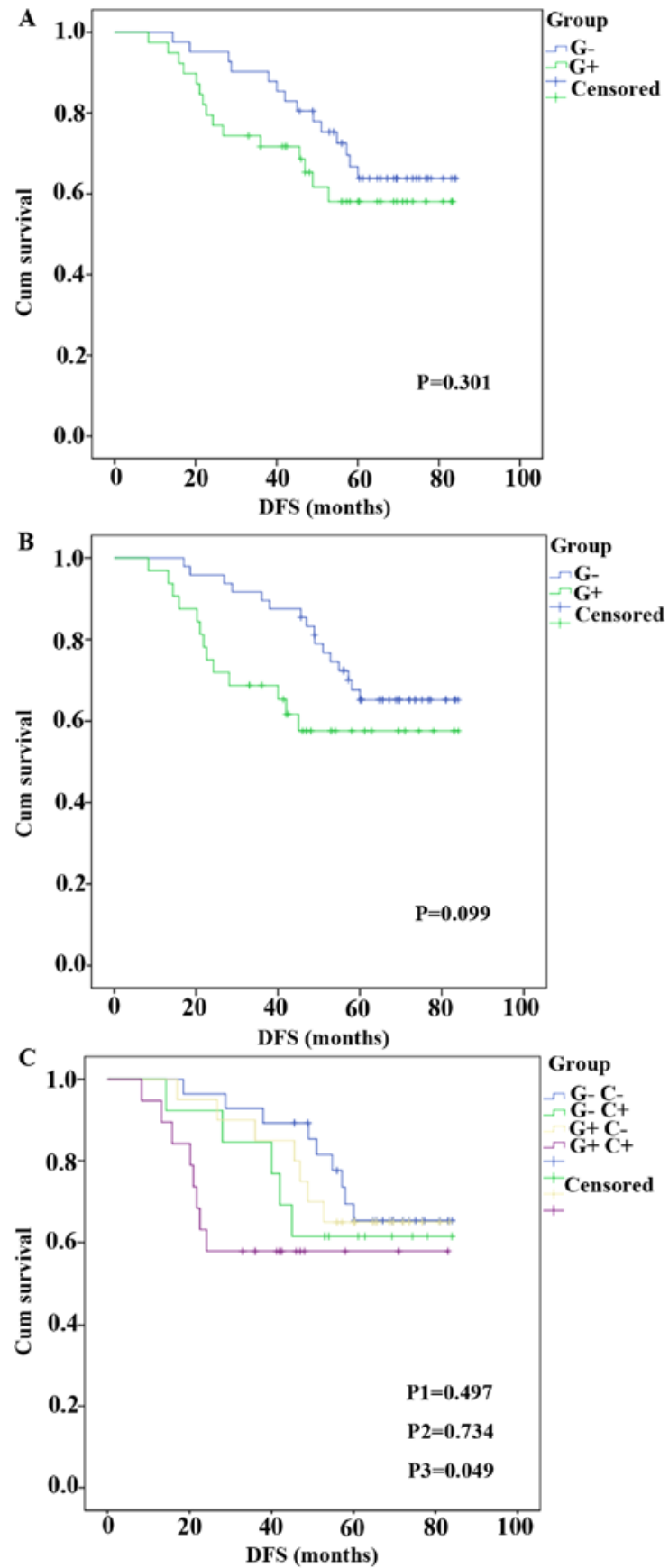

Figure 3. Association between GCS or CYP1A1 expression and DFS. DFS of patients in the (A) $\mathrm{GCS}^{+}$and $\mathrm{GCS}^{-}$groups, (B) CYP1A1 $1^{+}$and CYP1A1 groups, and (C) the GCS CYP1A1-, $\mathrm{GCS}^{+} \mathrm{CYP} 1 \mathrm{A1} 1^{+}, \mathrm{GCS}^{-} \mathrm{CYP} 1 \mathrm{~A} 1^{+}$ and $\mathrm{GCS}^{+} \mathrm{CYP} 1 \mathrm{~A} 1^{-}$groups. After adjustment using Bonferroni's correction, $\mathrm{P}<0.017(0.05 / 3)$ was defined as statistically significant. $\mathrm{P} 1=0.497$, $\mathrm{GCS}^{-} \mathrm{CYP} 1 \mathrm{~A} 1^{+}$vs. GCS ${ }^{-} \mathrm{CYP} 1 \mathrm{~A} 11^{-} \mathrm{P} 2=0.734, \mathrm{GCS}^{+} \mathrm{CYP} 1 \mathrm{~A} 1^{-}$vs GCS CYP1A1 ${ }^{-}$P3 $=0.049, \mathrm{GCS}^{+} \mathrm{CYP}^{-} \mathrm{A1}^{+}$vs. GCS-CYP1A1 . CYP1A1, cytochrome P450 family 1 subfamily A1; DFS, disease-free survival; GCS, glucosylceramide synthase.

Capecitabine for Residual Cancer as Adjuvant Therapy (44) and KATERINE (45) clinical trials demonstrated that NACT has become the preferred treatment strategy for patients with TNBC and HER-2-positive breast cancer in clinical practice. Numerous studies have previously highlighted the prognostic significance of pathological complete response (pCR) (9-11). A number of drugs, including as poly(ADP-ribose) polymerase inhibitors (46), vascular endothelial growth factor 
inhibitors (47) and immune checkpoint inhibitors $(48,49)$, have been applied in clinical trials to improve the pCR rate in breast cancer. Compared with that in other breast cancer subtypes, TNBC has a relatively high possibility of achieving pCR. However, this advantage could not be clearly translated into improved DFS or overall survival (OS) due to poor outcomes in the non-pCR groups $(50,51)$. Therefore, early identification of sensitive responders could provide definitive value for decision making with regards to the type of therapy for patients with TNBC. There is no universally approved marker for the prediction of the response to NACT (52). Therefore, the introduction of novel biomarkers could expand the repertoire of currently available clinical options and to accurately predict the response to NACT for patients with TNBC.

Anthracycline-taxanes are commonly used in clinical practice due to the lack of a standard treatment regimen for NACT (24). However, development of drug resistance to the available treatments is the primary barrier to TNBC treatment with NACT (53). Both GCS and CYP1A1 expression levels are associated with $\mathrm{P}$-glycoprotein expression and upregulate multidrug resistance protein 1 expression during the regulation of breast cancer drug resistance via $\beta$-catenin signaling (40,54-56). In a previous study, the expression levels of GCS were found to be associated with ER-positive $(\mathrm{P}=0.017)$ and HER-2-negative $(\mathrm{P}=0.007)$ invasive breast cancer (23). GCS is more highly expressed in younger patients ( $<35$ years) (23). However, the present study did not identify an association between age and GCS upregulation in patients with TNBC, although GCS upregulation was associated with tumor size and TNM staging. These differences may be due to the heterogeneity of TNBC. Zhang et al (22) previously reported that GCS expression was upregulated after NACT in ER-positive invasive breast cancer. The present study also detected a change in GCS expression in TNBC after NACT, the upregulation of which was associated with NACT in TNBC. CYP encodes enzymes involved in the metabolism of pharmacological agents (57). By activating or inactivating carcinogens and anticancer drugs, CYP serves an important role for the study of cancer and cancer treatments (58). Due to the overlapping substrate specificity between CYP and P-glycoprotein, numerous drug interactions can involve both P-glycoprotein and CYP (59). CYP1A1 is one of the most important isoforms responsible for the metabolic activation of pre-carcinogens (60). In the present study, the expression levels of CYP1A1 were associated with lymph node metastasis and TNM staging. This was consistent with the results of Wang and Wang (61). Another report previously revealed that the expression levels of CYP1A1 are associated with age or tumor grade in breast cancer (62). The present study did not identify a relationship between CYP1A1 and these two parameters, but it did reveal that the upregulation of CYP1A1 were associated with NACT. This suggested that the upregulation of GCS and CYP1A1 may be the underlying reason for NACT resistance in patients with TNBC. The mechanisms of GCS- and CYP1A1-induced chemoresistance to NACT in TNBC need to be confirmed by further in vitro experiments.

It is of interest to explore whether these two biomarkers are associated with each other and can provide useful prognosis information for patients with TNBC after undergoing NACT. Therefore, the association between GCS and CYP1A1 expression was next detected. The results revealed that they were positively correlated. $\mathrm{pCR}$ in the primary tumor following NACT is a strong predictor of freedom from recurrence and long-term survival (38). cCR is the disappearance of all lesions with nodes measuring $<10 \mathrm{~mm}$ and normal tumor markers. Measuring residual disease after neoadjuvant chemotherapy could improve the prognostic information that can be obtained from evaluating the pathologic complete response (pCR) (63). A number of studies have previously reported factors that affect the prognosis of patients with TNBC following NACT, including $\mathrm{C}-\mathrm{X}-\mathrm{C}$ motif chemokine ligand $8-\mathrm{C}-\mathrm{X}-\mathrm{C}$ motif chemokine receptor $1 / 2$ (64), pre-treatment neutrophil-lymphocyte ratio (65) and tumor-infiltrating lymphocytes (66). However, it remains to be difficult to introduce a biomarker into daily clinical use due to the lack of consistent evidence of clinical significance and operational barriers to clinical implementation $(62,64,65)$. In the present study, both GCS and CYP1A1 were associated with cCR. However, neither GCS nor CYP1A1 upregulation was associated with pCR or DFS. When these two biomarkers were analyzed together, the results revealed that combined GCS and CYP1A1 upregulation was associated with $\mathrm{pCR}(\mathrm{P}=0.031)$. The results also revealed a trend that patients in the $\mathrm{GCS}^{+} \mathrm{CYP} 1 \mathrm{~A} 1^{+}$group had a worse DFS rate, even if there was no statistically significance. The combination of these two biomarkers could also predict the prognosis of patients with TNBC undergoing NACT. If successful, it may differentiate patients who are at high risk of recurrence and need further therapy from patients with low risk of recurrence, avoiding the unnecessary long-term toxicity of chemotherapy. This will be of importance in the clinical setting in the future.

The present study has several limitations. The sample size was small and the follow-up time was relatively short, such that there was no statistical significance between the DFS rate of the $\mathrm{GCS}^{+} \mathrm{CYP} 1 \mathrm{~A} 1^{+}$group and the $\mathrm{GCS}^{-} \mathrm{CYP} 1 \mathrm{~A} 1^{-}$group. The present study was a retrospective single-center study. In addition, different NACT regimens, which may influence the pCR and DFS (67), were not evaluated. The follow-up time should be longer and the OS requires further analysis. Whether the $\beta$-catenin signaling pathway induced GCS and CYP1A1 expression after NACT needs to be explored in further in vitro experiments. Overall, future prospective studies with a large sample size and sufficient follow-up times are required to verify the results found in the present study.

In conclusion, the present study provided evidence that both GCS and CYP1A1 expression are important in patients with TNBC treated with NACT. Furthermore, they may help in classifying TNBC into subtypes with different responses to chemotherapy. Increased GCS and CYP1A1 expression after NACT could indicate a poor prognosis in patients with TNBC.

\section{Acknowledgements}

Not applicable.

\section{Funding}

The present study was supported by the Yantai Science and Technology Project (grant no. 2018SFGY111). 


\section{Availability of data and materials}

The datasets used and/or analyzed during the current study are available from the corresponding author on reasonable request.

\section{Authors' contributions}

JL and SW designed the study and analyzed the data and drafted the manuscript. CW performed the IHC. XK collected the clinical data. PS conceived and designed the study. All authors read and approved the final manuscript.

\section{Ethics approval and consent to participate}

Written informed consent was obtained from all individual participants included in the present study before treatment. The present study was conducted in accordance with the Declaration of Helsinki. The present study was approved by the Institutional Review Board, Medical Ethics Committee of Yantai Yuhuangding Hospital (Yantai, China).

\section{Patient consent for publication}

Not applicable.

\section{Competing interests}

The authors declare that they have no competing interests.

\section{References}

1. Allemani C, Weir HK, Carreira H, Harewood R, Spika D, Wang XS, Bannon F, Ahn JV, Johnson CJ, Bonaventure A, et al: Global surveillance of cancer survival 1995-2009: Analysis of individual data for $25,676,887$ patients from 279 population-based registries in 67 countries (CONCORD-2). Lancet 385 977-1010, 2015.

2. Pareja F and Reis-Filho JS: Triple-negative breast cancers-a panoply of cancer types. Nat Rev Clin Oncol 15: 347-348, 2018.

3. Wolff AC, Hammond MEH, Allison KH, Harvey BE, Mangu PB Bartlett JMS, Bilous M, Ellis IO, Fitzgibbons P, Hanna W, et al: Human epidermal growth factor receptor 2 testing in breast cancer: American society of clinical oncology/college of american pathologists clinical practice guideline focused update. J Clin Oncol 36: 2105-2122, 2018.

4. Keenan TE and Tolaney SM: Role of immunotherapy in triple-negative breast cancer. J Natl Compr Canc Netw 18: 479-489, 2020.

5. Garrido-Castro AC, Lin NU and Polyak K: Insights into molecular classifications of triple-negative breast cancer: Improving patient selection for treatment. Cancer Discov 9: 176-198, 2019.

6. Chaudhary LN, Wilkinson KH and Kong A: Triple-negative breast cancer: Who should receive neoadjuvant chemotherapy? Surg Oncol Clin N Am 27: 141-153, 2018.

7. Lebert JM, Lester R, Powell E, Seal M and McCarthy J: Advances in the systemic treatment of triple-negative breast cancer. Curr Oncol 25 (Suppl 1): S142-S150, 2018.

8. Asaoka M, Narui K, Suganuma N, Chishima T, Yamada A, Sugae S, Kawai S, Uenaka N, Teraoka S, Miyahara K, et al: Clinical and pathological predictors of recurrence in breast cancer patients achieving pathological complete response to neoadjuvant chemotherapy. Eur J Surg Oncol 45: 2289-2294, 2019.

9. De Mattos-Arruda L, Shen R, Reis-Filho JS and Cortés J: Translating neoadjuvant therapy into survival benefits: One size does not fit all. Nat Rev Clin Oncol 13: 566-579, 2016.

10. Walsh EM, Shalaby A, O'Loughlin M, Keane N, Webber MJ, Kerin MJ, Keane MM, Glynn SA and Callagy GM: Outcome for triple negative breast cancer in a retrospective cohort with an emphasis on response to platinum-based neoadjuvant therapy. Breast Cancer Res Treat 174: 1-13, 2019.
11. Telli ML, Timms KM, Reid J, Hennessy B, Mills GB, Jensen KC, Szallasi Z, Barry WT, Winer EP, Tung NM, et al: Homologous recombination deficiency (HRD) score predicts response to platinum-containing neoadjuvant chemotherapy in patients with triple-negative breast cancer. Clin Cancer Res 22: 3764-3773, 2016.

12. Ryspayeva D, Lyashenko A, Dosenko I, Kostryba O, Koshyk O, Krotevych $M$ and Smolanka I: Predictive factors of pathological response to neoadjuvant chemotherapy in patients with breast cancer. J BUON 25: 168-175, 2020.

13. von Minckwitz G, Untch M, Blohmer JU, Costa SD, Eidtmann H, Fasching PA, Gerber B, Eiermann W, Hilfrich J, Huober J, et al: Definition and impact of pathologic complete response on prognosis after neoadjuvant chemotherapy in various intrinsic breast cancer subtypes. J Clin Oncol 30: 1796-1804, 2012.

14. Miyashita M and Ishida T: Prospect of immunotherapy in neoadjuvant/adjuvant treatment for early breast cancer. Chin Clin Oncol 9: 28, 2020.

15. LoiblS, Weber KE, Timms KM,Elkin EP,Hahnen E, Fasching PA, Lederer B, Denkert C, Schneeweiss A, Braun S, et al: Survival analysis of carboplatin added to an anthracycline/taxane-based neoadjuvant chemotherapy and HRD score as predictor of response-final results from GeparSixto. Ann Oncol 29: 2341-2347, 2018

16. Mohammed AA, Elsayed FM, Algazar M, Rashed HE and Anter AH: Neoadjuvant chemotherapy in triple negative breast cancer: Correlation between androgen receptor expression and pathological response. Asian Pac J Cancer Prev 21: 563-568, 2020.

17. Xu HB, Xu LZ, Li L, Fu J and Mao XP: Reversion of P-glycoprotein-mediated multidrug resistance by guggulsterone in multidrug-resistant human cancer cell lines. Eur J Pharmacol 694: 39-44, 2012.

18. Liu YY, Patwardhan GA, Xie P, Gu X, Giuliano AE and Cabot MC: Glucosylceramide synthase, a factor in modulating drug resistance, is overexpressed in metastatic breast carcinoma. Int J Oncol 39: 425-431, 2011.

19. Sun Y, Zhang T, Gao P, Meng B, Gao Y, Wang X, Zhang J, Wang H, Wu X, Zheng W and Zhou G: Targeting glucosylceramide synthase downregulates expression of the multidrug resistance gene MDR1 and sensitizes breast carcinoma cells to anticancer drugs. Breast Cancer Res Treat 121: 591-599, 2010.

20. Itoh M, Kitano T, Watanabe M, Kondo T, Yabu T, Taguchi Y, Iwai K, Tashima M, Uchiyama T and Okazaki T: Possible role of ceramide as an indicator of chemoresistance: Decrease of the ceramide content via activation of glucosylceramide synthase and sphingomyelin synthase in chemoresistant leukemia. Clin Cancer Res 9: 415-423, 2003.

21. Boojar MMA, Boojar MMA, Golmohammad S and Bahrehbar I: Data on cell survival, apoptosis, ceramide metabolism and oxidative stress in A-494 renal cell carcinoma cell line treated with hesperetin and hesperetin-7-O-acetate. Data Brief 20: 596-601, 2018.

22. Zhang X, Wu X, Su P, Gao Y, Meng B, Sun Y, Li L, Zhou Z and Zhou G: Doxorubicin influences the expression of glucosylceramide synthase in invasive ductal breast cancer. PLoS One 7: e48492, 2012.

23. Liu J, Sun P, Sun Y, Liu A, You D, Jiang F and Sun Y: Expression of glucosylceramide synthase in invasive ductal breast cancer may be correlated with high estrogen receptor status and low HER-2 status. Diagn Pathol 9: 22, 2014.

24. Harbeck N and Gluz O: Neoadjuvant therapy for triple negative and HER2-positive early breast cancer. Breast 34 (Suppl 1): S99-S103, 2017.

25. Michael $\mathrm{M}$ and Doherty MM: Tumoral drug metabolism: Overview and its implications for cancer therapy. J Clin Oncol 23: 205-229, 2005.

26. Runge D, Köhler C, Kostrubsky VE, Jäger D, Lehmann T, Runge DM, May U, Stolz DB, Strom SC, Fleig WE and Michalopoulos GK: Induction of cytochrome P450 (CYP)1A1, CYP1A2, and CYP3A4 but not of CYP2C9, CYP2C19, multidrug resistance (MDR-1) and multidrug resistance associated protein (MRP-1) by prototypical inducers in human hepatocytes. Biochem Biophys Res Commun 273: 333-341, 2000.

27. Yan YE, Wang $\mathrm{H}$ and Feng $\mathrm{YH}$ : Alterations of placental cytochrome P450 1A1 and P-glycoprotein in tobacco-induced intrauterine growth retardation in rats. Acta Pharmacol Sin 26: $1387-1394,2005$. 
28. Zhang J, Song J, Liang X, Yin Y, Zuo T, Chen D and Shen Q: Hyaluronic acid-modified cationic nanoparticles overcome enzyme CYP1B1-mediated breast cancer multidrug resistance. Nanomedicine (Lond) 14: 447-464, 2019.

29. Sorf A, Hofman J, Kučera R, Staud F and Ceckova M: Ribociclib shows potential for pharmacokinetic drug-drug interactions being a substrate of $\mathrm{ABCB} 1$ and potent inhibitor of ABCB1, ABCG2 and CYP450 isoforms in vitro. Biochem Pharmacol 154: 10-17, 2018.

30. Chen Y, Huang W, Chen F, Hu G, Li F, Li J and Xuan A: Pregnane $\mathrm{X}$ receptors regulate CYP2C8 and P-glycoprotein to impact on the resistance of NSCLC cells to Taxol. Cancer Med 5: 3564-3571, 2016

31. Yu KD, Liu GY, Zhou XY, Zhou Y, Wu J, Chen CM, Shen ZZ and Shao ZM: Association of HER-2 copy number and HER-2/CEP-17 ratio with neoadjuvant taxane-containing chemotherapy sensitivity in locally advanced breast cancer. Oncologist 17: 792-800, 2012.

32. Azam F, Latif MF, Farooq A, Tirmazy SH, AlShahrani S, Bashir S and Bukhari N: Performance status assessment by using ECOG (Eastern cooperative oncology group) score for cancer patients by oncology healthcare professionals. Case Rep Oncol 12: 728-736, 2019.

33. Zaheed M, Wilcken N, Willson ML, O'Connell DL and Goodwin A: Sequencing of anthracyclines and taxanes in neoadjuvant and adjuvant therapy for early breast cancer. Cochrane Database Syst Rev 2: Cd012873, 2019.

34. Rastogi P, Anderson SJ, Bear HD, Geyer CE, Kahlenberg MS Robidoux A, Margolese RG, Hoehn JL, Vogel VG, Dakhil SR, et al: Preoperative chemotherapy: Updates of national surgical adjuvant breast and bowel project protocols B-18 and B-27. J Clin Oncol 26: 778-785, 2008

35. Nakatsukasa K, Koyama H, Oouchi Y, Imanishi S, Mizuta N, Sakaguchi K, Fujita Y, Fujiwara I, Kotani T, Matsuda T, et al: Docetaxel and cyclophosphamide as neoadjuvant chemotherapy in HER 2-negative primary breast cancer. Breast Cancer 24: 63-68, 2017.

36. Schneeweiss A, Möbus V, Tesch H, Hanusch C, Denkert C, Lübbe K, Huober J, Klare P, Kümmel S, Untch M, et al: Intense dose-dense epirubicin, paclitaxel, cyclophosphamide versus weekly paclitaxel, liposomal doxorubicin (plus carboplatin in triple-negative breast cancer) for neoadjuvant treatment of high-risk early breast cancer (GeparOcto-GBG 84): A randomised phase III trial. Eur J Cancer 106: 181-192, 2019.

37. Jang N, Choi JE, Kang SH and Bae YK: Validation of the pathological prognostic staging system proposed in the revised eighth edition of the AJCC staging manual in different molecular subtypes of breast cancer. Virchows Arch 474: 193-200, 2019.

38. Cortazar P and Geyer CE Jr: Pathological complete response in neoadjuvant treatment of breast cancer. Ann Surg Oncol 22: 1441-1446, 2015.

39. Ghobrial FEI, Eldin MS, Razek AAKA, Atwan NI and Shamaa SSA: Computed tomography assessment of hepatic metastases of breast cancer with revised response evaluation criteria in solid tumors (RECIST) criteria (version 1.1): Inter-observer agreement. Pol J Radiol 82: 593-597, 2017.

40. Al-Dhfyan A, Alhoshani A and Korashy HM: Aryl hydrocarbon receptor/cytochrome P450 1A1 pathway mediates breast cancer stem cells expansion through PTEN inhibition and beta-catenin and Akt activation. Mol Cancer 16: 14, 2017

41. Liu J, Zhang X, Liu A, Zhang D, Su Y, Liu Y, You D, Yuan L, Kong X, Wang X and Sun P: Altered methylation of glucosylceramide synthase promoter regulates its expression and associates with acquired multidrug resistance in invasive ductal breast cancer. Oncotarget 7: 36755-36766, 2016.

42. Livak KJ and Schmittgen TD: Analysis of relative gene expression data using real-time quantitative PCR and the 2(-Delta Delta C(T)) method. Methods 25: 402-408, 2001.

43. Yam C, Mani SA and Moulder SL: Targeting the molecular subtypes of triple negative breast cancer: Understanding the diversity to progress the field. Oncologist 22: 1086-1093, 2017.

44. Ozaki A, Takita M and Tanimoto T: A call for improved transparency in financial aspects of clinical trials: A case study of the CREATE-X trial in the New England journal of medicine. invest New Drugs 36: 517-522, 2018.

45. Pusztai L, Foldi J, Dhawan A, DiGiovanna MP and Mamounas EP: Changing frameworks in treatment sequencing of triple-negative and HER2-positive, early-stage breast cancers. Lancet Oncol 20: e390-e396, 2019
46. Diana A, Carlino F, Franzese E, Oikonomidou O, Criscitiello C, De Vita F, Ciardiello F and Orditura M: Early triple negative breast cancer: Conventional treatment and emerging therapeutic landscapes. Cancers (Basel) 12: 819, 2020.

47. Barton MK: Bevacizumab in neoadjuvant chemotherapy increases the pathological complete response rate in patients with triple-negative breast cancer. CA Cancer J Clin 64: 155-156, 2014.

48. Schmid P, Salgado R, Park YH, Muñoz-Couselo E, Kim SB, Sohn J, Im SA, Foukakis T, Kuemmel S, Dent R, et al: Pembrolizumab plus chemotherapy as neoadjuvant treatment of high-risk, early-stage triple-negative breast cancer: Results from the phase $1 \mathrm{~b}$ open-label, multicohort KEYNOTE-173 study. Ann Oncol 31: 569-581, 2020.

49. Garufi G, Palazzo A, Paris I, Orlandi A, Cassano A, Tortora G, Scambia G, Bria E and Carbognin L: Neoadjuvant therapy for triple-negative breast cancer: Potential predictive biomarkers of activity and efficacy of platinum chemotherapy, PARP- and immune-checkpoint-inhibitors. Expert Opin Pharmacother 21: 687-699, 2020

50. Wang RX, Chen S, Jin X and Shao ZM: Value of Ki-67 expression in triple-negative breast cancer before and after neoadjuvant chemotherapy with weekly paclitaxel plus carboplatin. Sci Rep 6: 30091, 2016.

51. Carey LA, Dees EC, Sawyer L, Gatti L, Moore DT, Collichio F, Ollila DW, Sartor CI, Graham ML and Perou CM: The triple negative paradox: Primary tumor chemosensitivity of breast cancer subtypes. Clin Cancer Res 13: 2329-2334, 2007.

52. Sano H, Wada S, Eguchi H, Osaki A, Saeki T and Nishiyama M: Quantitative prediction of tumor response to neoadjuvant chemotherapy in breast cancer: Novel marker genes and prediction model using the expression levels. Breast Cancer 19: 37-45, 2012.

53. Nøhr-Nielsen A, Bagger SO, Brünner N, Stenvang J and Lund TM: Pharmacodynamic modelling reveals synergistic interaction between docetaxel and SCO-101 in a docetaxel-resistant triple negative breast cancer cell line. Eur J Pharm Sci 148: $105315,2020$.

54. Zhang X, Li J, Qiu Z, Gao P, Wu X and Zhou G: Co-suppression of MDR1 (multidrug resistance 1) and GCS (glucosylceramide synthase) restores sensitivity to multidrug resistance breast cancer cells by RNA interference (RNAi). Cancer Biol Ther 8: 1117-1121, 2009.

55. Weiss J, Gajek T, Köhler BC and Haefeli WE: Venetoclax (ABT-199) might act as a perpetrator in pharmacokinetic drug-drug interactions. Pharmaceutics 8: 5, 2016.

56. Liu YY, Gupta V, Patwardhan GA, Bhinge K, Zhao Y, Bao J, Mehendale H, Cabot MC, Li YT and Jazwinski SM: Glucosylceramide synthase upregulates MDR1 expression in the regulation of cancer drug resistance through $\mathrm{cSrc}$ and beta-catenin signaling. Mol Cancer 9: 145, 2010.

57. Kivistö KT, Kroemer HK and Eichelbaum M: The role of human cytochrome P450 enzymes in the metabolism of anticancer agents: Implications for drug interactions. Br J Clin Pharmacol 40: 523-530, 1995.

58. Reed L, Arlt VM and Phillips DH: The role of cytochrome P450 enzymes in carcinogen activation and detoxication: An in vivo-in vitro paradox. Carcinogenesis 39: 851-859, 2018

59. Wilson A, Urquhart BL, Ponich T, Chande N, Gregor JC, Beaton $\mathrm{M}$ and Kim RB: Crohn's disease is associated with decreased CYP3A4 and P-glycoprotein protein expression. Mol Pharm 16: 4059-4064, 2019.

60. Stiborová M, Martínek V, Rýdlová H, Koblas T and Hodek P: Expression of cytochrome P450 1A1 and its contribution to oxidation of a potential human carcinogen 1-phenylazo-2-naphthol (Sudan I) in human livers. Cancer Lett 220: 145-154, 2005.

61. Wang H and Wang WJ: Relationship between CYP1A1 polymorphisms and invasion and metastasis of breast cancer. Asian Pac J Trop Med 6: 835-838, 2013.

62. Hafeez S,Ahmed A, Rashid AZ and Kayani MA: Down-regulation of CYP1A1 expression in breast cancer. Asian Pac J Cancer Prev 13: 1757-1760, 2012.

63. Symmans WF, Peintinger F, Hatzis C, Rajan R, Kuerer H, Valero V, Assad L, Poniecka A, Hennessy B, Green M, et al: Measurement of residual breast cancer burden to predict survival after neoadjuvant chemotherapy. J Clin Oncol 25: 4414-4422, 2007. 
64. Wang RX, Ji P, Gong Y, Shao ZM and Chen S: Value of CXCL8-CXCR $1 / 2$ axis in neoadjuvant chemotherapy for triple-negative breast cancer patients: A retrospective pilot study. Breast Cancer Res Treat 181: 561-570, 2020.

65. Dan J, Tan J, Huang J, Zhang X, Guo Y, Huang Y and Yang J: The dynamic change of neutrophil to lymphocyte ratio is predictive of pathological complete response after neoadjuvant chemotherapy in breast cancer patients. Breast Cancer 27: 982-988, 2020.

66. Ochi T, Bianchini G, Ando M, Nozaki F, Kobayashi D Criscitiello C, Curigliano G, Iwamoto T, Niikura N, Takei H, et al: Predictive and prognostic value of stromal tumour-infiltrating lymphocytes before and after neoadjuvant therapy in triple negative and HER2-positive breast cancer. Eur J Cancer 118: 41-48, 2019.
67. Sikov WM, Berry DA, Perou CM, Singh B, Cirrincione CT, Tolaney SM, Kuzma CS, Pluard TJ, Somlo G, Port ER, et al: Impact of the addition of carboplatin and/or bevacizumab to neoadjuvant once-per-week paclitaxel followed by dose-dense doxorubicin and cyclophosphamide on pathologic complete response rates in stage II to III triple-negative breast cancer: CALGB 40603 (Alliance). J Clin Oncol 33: 13-21, 2015. 